\title{
Efeitos da radiação gama na cor, capacidade antioxidante e perfil de ácidos graxos em amendoim (Arachis hypogaea L.)
}

\author{
Gamma radiation effects at color, antioxidant capacity and fatty acid profile in peanut (Arachis hypogaea L.)
}

\author{
Adriano Costa de CAMARGO ${ }^{1}$, Solange Guidolin CANNIATTI-BRAZACA ${ }^{2 *}$, \\ Débora Niero MANSI², Maria Antonia Calori DOMINGUES², Valter ARTHUR ${ }^{3}$
}

\begin{abstract}
Resumo
A irradiação gama é eficiente para eliminar a contaminação fúngica em grãos de amendoim. Este apresenta proteínas de alto valor biológico, minerais, vitaminas E, complexo B e alta concentração de lipídios. Este trabalho teve como objetivo avaliar o efeito da aplicação de radiações gama na cor, fenólicos totais, atividade antioxidante e perfil de ácidos graxos em amendoim (Arachis hypogaea L.). Os cultivares IAC-Tatu ST e IAC-Runner 886 foram submetidos a radiações gama com doses de 5,0; 7,5; 10,0; e 15,0 kGy e armazenados em temperatura ambiente. Não foram verificadas diferenças significativas na cor dos amendoins IAC-Tatu ST. Diferenças significativas foram detectadas para a luminosidade e o Croma do IAC-Runner 886. Os fenólicos totais diferiram significativamente entre o controle com 33,27 mg. $\mathrm{g}^{-1}$ e o tratamento com $10,0 \mathrm{kGy}$ com 58,60 mg.g ${ }^{-1}$ no IAC-Tatu ST, neste parâmetro não foram observadas diferenças significativas no IAC-Runner 886, cujo controle foi $51,59 \mathrm{mg} \cdot \mathrm{g}^{-1}$. Para atividade antioxidante não foi verificada diferença significativa com a dose de 10,0 kGy, recomendada para eliminação fúngica de amendoim. Na dose de 10,0 kGy, verificou-se a diminuição de ácidos graxos saturados, o aumento dos insaturados e o aumento de ácido linoleico. A relação oleico/linoleico diminuiu, justificando novos estudos correlacionando armazenamento e estabilidade oxidativa. Palavras-chave: antioxidantes; lipídios; irradiação; cultivares; amendoim; Arachis hypogaea L.
\end{abstract}

\begin{abstract}
Irradiation is efficient at extincting fungi contamination in peanuts. Peanuts have high biologic value protein, minerals, vitamin E, complex B, and high concentration of lipids. The objective of this research is to evaluate the gamma irradiation effect on color, total phenolic, antioxidant activity, and fatty acid profile in peanuts (Arachis hypogaea L.). Cultivars IAC-Tatu ST and IAC-Runner 886 were submitted to gamma radiation with doses of 5.0; 7.5; 10.0, and $15.0 \mathrm{kGy}$ and storage at room temperature. There was no significant difference in the color of IAC-Tatu ST. However, significant difference was found in the luminosity and Chroma in IAC-Runner 886. Total fenolics differed from the control with $33.27 \mathrm{mg} . \mathrm{g}^{-1}$ and treatment dose of $10.0 \mathrm{kGy}$ with $58.60 \mathrm{mg} \cdot \mathrm{g}^{-1}$ in IAC-Tatu ST. This parameter not had significant difference in IAC-Runner 886 and the control with $51.59 \mathrm{mg} . \mathrm{g}^{-1}$. The antioxidant activity did not present significant difference with a dose of $10.0 \mathrm{kGy}$, recommended for the elimination of fungi in peanuts. The dose of $10.0 \mathrm{kGy}$ showed a decrease in saturated fatty acids, increase in unsaturated fatty acids, and an increase in linolleic acid. The oleic/linoleic relation decreased justifying further research correlating storage and oxidative stability. Keywords: antioxidants; lipids; irradiation; cultivars; peanut.; Arachis hypogaea L.
\end{abstract}

\section{Introdução}

A planta do amendoim é uma dicotiledônea, da família Leguminoseae. Dentre as inúmeras espécies conhecidas, as mais importantes são do gênero Arachis hypogaea L. (TASSO JUNIOR; MARQUES; NOGUEIRA, 2004). No Brasil, 88,6\% da produção nacional de amendoim encontra-se na região sudeste (83,2\% em São Paulo); 8,3\% do total é produzido na região sul; e $2,9 \%$ na região nordeste. O amendoim é uma cultura oleaginosa de importância mundial. No Brasil, na safra 2006/2007, a produção foi de 225.700 toneladas (MARTINS, 2007). Dentro do Estado de São Paulo, destacam-se como regiões produtoras, Ribeirão Preto e Marília. Em Ribeirão Preto, o amendoim assume especial importância por estar entre as culturas de ciclo curto, podendo ocupar áreas de reforma de canaviais, contando ainda a região com empresas produtoras de sementes (FAGUNDES, 2002).

Os dois principais constituintes do amendoim são a proteína, que varia de 25 a 30\%, e os lipídios, entre 27 e $52 \%$. As variedades comerciais brasileiras usualmente apresentam teor de óleo que oscila de 45 a 50\% (TASSO JUNIOR; MARQUES; NOGUEIRA, 2004). A composição de ácidos graxos em grãos de amendoim varia entre cultivares, sendo a relação entre ácidos Oleico e Linoleico $(\mathrm{O} / \mathrm{L})$ determinante da vida de prateleira do amendoim ou de produtos que contenham amendoim em sua composição (SANTOS; GONDIM; FREIRE, 2006). Quanto maior a relação oleico/linoleico, maior o tempo de conservação (MARTIN et al., 2006).

\footnotetext{
Recebido para publicação em 17/4/2008

Aceito para publicação em 3/1/2009 (003435)

Ciências dos Alimentos, Departamento de Agroindústria, Alimentos e Nutrição, Escola Superior de Agricultura "Luiz de Queiroz" - ESALQ, Universidade de São Paulo - USP, Piracicaba - SP, Brasil

2 Departamento de Agroindústria, Alimentos e Nutrição, Escola Superior de Agricultura "Luiz de Queiroz" - ESALQ, Universidade de São Paulo - USP, Av. Pádua Dias, 11, CP 9, CEP 13418-900, Piracicaba - SP, Brasil.E-mail: sgcbraza@usp.br.

${ }_{3}^{3}$ Laboratório de Irradiação de Alimentos e Radioentomologia, Centro de Energia Nuclear na Agricultura, Universidade de São Paulo - USP, Piracicaba - SP, Brasil

${ }^{*}$ A quem a correspondência deve ser enviada
} 
A carência alimentar por produtos proteicos é elevada devido, sobretudo, ao baixo consumo dos alimentos de origem animal, cujo preço é, em geral, inacessível para grande parte da população. O consumo do amendoim, in natura ou em derivados, pode minimizar esta carência, além de enriquecer a dieta. É um alimento altamente calórico, proteico e rico em vitaminas do complexo B e E (SANTOS; GONDIM; FREIRE, 2006).

A irradiação de alimentos é um processo físico que envolve a exposição do alimento, embalado ou não, a um dos três tipos de energia ionizante: radiação gama, raios X ou feixe de elétrons em uma sala ou câmara especial de processamento, por um tempo determinado. A fonte mais usada para processamento de alimentos é a de radiação gama, proveniente do radioisótopo Cobalto-60 (DULLEY, 2002).

O amendoim é um dos grãos mais susceptíveis à contaminação por aflatoxinas em função do sistema de produção que é dependente do controle da umidade em todas as etapas da cadeia produtiva. As aflatoxinas, que são identificadas como o principal perigo na cadeia produtiva do amendoim, são produzidas por quatro espécies de fungos do gênero Aspergillus da secção Flavi: A. flavus, A. parasiticus, A. nomius e A. pseudotamarii, sendo que apenas o A. flavus e o A. parasiticus são economicamente importantes (COUNCIL..., 2003).

A contaminação com aflatoxinas na pré-colheita é afetada pela linhagem fúngica, densidade de inóculo, umidade e temperatura do solo, danos biológicos ou mecânicos. A contaminação após o arranquio do amendoim depende principalmente do teor de umidade. $\mathrm{O}$ amendoim em casca deve ser seco e armazenado com 10-11\% de umidade ou inferior. As estruturas de armazenamento devem ser limpas, protegidas das condições climáticas e livres de infestações de insetos e roedores (WILSON, 1995).

Prado et al. (2006) relataram que a irradiação gama reduziu a contaminação fúngica em amendoim, previamente desinfetado, nas três doses utilizadas (1, 5 e $10 \mathrm{kGy})$ e durante todo o intervalo de tempo do experimento $(0,20$, 60 e 180 dias). A partir da dose de $10 \mathrm{kGy}$, não foi observado crescimento fúngico, mesmo após 6 meses de armazenamento à temperatura ambiente, independentemente do processo prévio de desinfecção.

Toledo et al. (2007), estudando soja, que é uma leguminosa semelhante ao amendoim, observaram que doses de 0, 2, 4 e $8 \mathrm{kGy}$ aplicadas a diferentes cultivares não apresentaram diferenças significativas $(\mathrm{p} \leq 0,05)$ para as porcentagens lipídicas presentes.

\section{Objetivo}

A pesquisa teve por objetivo avaliar o comportamento físico e físico-químico causado pela irradiação em dois cultivares de amendoim (Arachis hypogaea L.).

\section{Material e métodos}

\subsection{Matéria-prima}

Foram utilizados dois cultivares de amendoim, IAC-Tatu ST e IAC-Runner 886, provenientes da Região de Ribeirão Preto - SP, safra 2006/2007.
Os grãos de amendoins foram irradiados com raios gama provenientes do Cobalto- 60 em doses de 0,0 (Controle); 5,0; 7,5; 10,0; e 15,0 kGy, permanecendo armazenados em sacos plásticos à temperatura ambiente até a conclusão dos testes. A irradiação foi conduzida em irradiador tipo Gammacell da Nordion, no Centro de Energia Nuclear na Agricultura - CENA/USP, em Piracicaba - SP, cuja taxa de dose foi de 0,635 kGy/hora.

\subsection{Análise de cor}

As análises de cor foram conduzidas utilizandose colorímetro Minolta e expressas as medidas em $\mathrm{L}^{*}$ (luminosidade), $\mathrm{a}^{\star}, \mathrm{e} \mathrm{b}^{\star}$. Os valores de $\mathrm{a}^{\star} \mathrm{e} \mathrm{b}^{\star}$ foram utilizados para cálculo do $\mathrm{C}$ (Croma) e $\mathrm{H}^{\circ}$ (Ângulo Hue). Através das seguintes Equações 1 e 2:

$C=\left(a^{2}+b^{2}\right)^{1 / 2}$

$\mathrm{H}^{\mathrm{o}}=\operatorname{arctg}(\mathrm{b} / \mathrm{a})$

\subsection{Fenólicos totais}

A determinação da concentração de fenólicos totais foi realizada utilizando-se a metodologia descrita por Swain e Hillis (1959) e como extrator o metanol, com adição posterior do reagente Folin-Denis, saturação com carbonato de sódio e leitura da absorbância a $725 \mathrm{~nm}$. O padrão utilizado para realização da curva padrão foi a catequina, e os resultados foram expressos em mg.g $\mathrm{g}^{-1}$ de amostra.

\subsection{Atividade antioxidante pelo método DPPH}

A capacidade antioxidante das diferentes amostras foi medida segundo método proposto por Brand-William, Cuvier e Berset (1995), utilizando 1,1-difenil-2-picrilhidrazil (DPPH). Para a medida, foi utilizado extrato de etanol na concentração $1,5 \mathrm{~g} \cdot 10 \mathrm{~mL}^{-1}$ do cultivar IAC-Tatu ST e $0,5 \mathrm{~g} \cdot 10 \mathrm{~mL}^{-1}$ do cultivar IAC-Runner 886. A absorbância da amostra foi medida a $517 \mathrm{~nm}, \mathrm{em} \mathrm{t}=0 \mathrm{e} \mathrm{t}=45$ minutos, e os resultados foram expressos em porcentagem de DPPH reduzido segundo a Equação 3:

$\%$ DPPH reduzido $=\{[($ Abs controle - Abs amostra $) /$ Abs controle $] \times 100\}(3)$

\subsection{Atividade antioxidante pelo método ABTS}

A atividade antioxidante foi analisada utilizando-se extrato etanólico 1,5 g. $10 \mathrm{~mL}^{-1}$ para o cultivar IAC-Tatu ST e 0,5 g. $10 \mathrm{~mL}^{-1}$ para o cultivar IAC-Runner 886 . O TEAC baseia-se na inibição por antioxidantes do cátion radical 2,2-azinobis(3-etilbenzotiazolina-6-sulfonato, sal de diamônio) (C18H24N6O6S4, M.M. 548,7 g.mol ${ }^{-1}$, ABTS+•), que apresenta absorbância característica primária em $415 \mathrm{~nm}$ e absorções secundárias em 660, 734 e 820 nm (VASCONCELOS et al., 2007). Foi utilizado o padrão TEAC descrito por Berg et al. (1999) e Re et al. (1999) que usa a determinação dos valores de TEAC, com algumas modificações. A TEAC foi calculada em relação à solução de Trolox (ARTS et al., 2004). A solução estoque de Trolox foi diluída em 5 pontos (2,5 $\mu \mathrm{M}$ (1:799); $5 \mu \mathrm{M}$ (1:399); $10 \mu \mathrm{M}$ (1:199); $15 \mu \mathrm{M}(1: 132))$ e a curva padrão foi preparada. Os resultados foram expressos em equivalente de atividade antioxidante ao Trolox (TEAC) ( $\mu$ mol TEAC. ${ }^{-1}$ de amostra). 


\subsection{Perfil de ácidos graxos}

As amostras de ácidos graxos foram extraídas dos amendoins utilizando-se adaptação do método de Folch, Lees e Stanley (1957), e metiladas pelo método de Kramer et al. (1997). Para a determinação de ácidos graxos foi utilizado um cromatógrafo gasoso HP 5890, equipado com detector por ionização em chama, coluna DB-23 (60 m de comprimento $\times 0,25 \mathrm{~mm}$ de diâmetro interno, I.D. $0,25 \mu \mathrm{m}$ ), as condições cromatográficas foram: temperatura da coluna, 130 a $230^{\circ} \mathrm{C}$; gás de arraste hélio, numa vazão de $1,5 \mathrm{~mL} /$ minuto.

\section{Resultados e discussão}

\subsection{Análise de cor}

As Tabelas 1 e 2 mostram os dados para luminosidade (L), croma (C) e ângulo Hue $\left(\mathrm{H}^{\circ}\right)$ para os dois cultivares de amendoim analisados.

Para o cultivar IAC Tatu-ST, nenhum dos tratamentos ocasionou diferença significativa em nível de $5 \%$, para nenhum dos parâmetros de cor estudados.

No cultivar IAC-Runner 886 houve diferenças significativas em nível de 5\% para a luminosidade na dose de 5,0 kGy em relação ao grupo controle e à dose de 10,0 kGy. Ambas as diferenças tiveram o mesmo comportamento, ou seja, com o aumento das doses houve diminuição da luminosidade do amendoim. Com relação ao croma, podemos verificar que a dose de 15,0 kGy difere estatisticamente do grupo controle, o que evidencia que com o aumento da dose houve leve escurecimento do amendoim. $\mathrm{O}$ ângulo Hue não diferiu estatisticamente em nenhuma das cultivares.

\subsection{Fenólicos totais}

A Tabela 3 apresenta os resultados das análises de compostos fenólicos totais dos amendoins irradiados.

No cultivar IAC-Tatu ST, pode ser percebida linearidade do aumento de compostos fenólicos com o aumento das doses aplicadas. Isso se interrompe apenas na dose de 15,0 kGy, quando o teor fica menor do que o grupo controle. O aumento do teor de

Tabela 1. Efeitos da radiação gama nos parâmetros ${ }^{1}$ de cor do amendoim cultivar IAC-Tatu ST.

\begin{tabular}{lccccc}
\hline $\begin{array}{c}\text { IAC - } \\
\text { Tatu ST }\end{array}$ & Controle & $5,0 \mathrm{kGy}$ & $7,5 \mathrm{kGy}$ & $10,0 \mathrm{kGy}$ & $15,0 \mathrm{kGy}$ \\
\hline $\mathrm{L}$ & $30,72 \pm 6,5^{\mathrm{a} 2}$ & $28,03 \pm 7,1^{\mathrm{a}}$ & $27,47 \pm 4,2^{\mathrm{a}}$ & $25,88 \pm 4,2^{\mathrm{a}}$ & $28,82 \pm 5,8^{\mathrm{a}}$ \\
$\mathrm{C}$ & $33,69 \pm 2,0^{\mathrm{a}}$ & $31,01 \pm 3,1^{\mathrm{a}}$ & $32,29 \pm 0,9^{\mathrm{a}}$ & $33,46 \pm 2,1^{\mathrm{a}}$ & $32,50 \pm 2,3^{\mathrm{a}}$ \\
$\mathrm{H}^{\mathrm{o}}$ & $0,548 \pm 0,0^{\mathrm{a}}$ & $0,608 \pm 0,1^{\mathrm{a}}$ & $0,563 \pm 0,0^{\mathrm{a}}$ & $0,567 \pm 0,1^{\mathrm{a}}$ & $0,605 \pm 0,0^{\mathrm{a}}$ \\
\hline
\end{tabular}

${ }^{1}$ Os dados são a média de nove repetições \pm desvio padrão; $\mathrm{e}^{2}$ Letras diferentes na horizontal indicam diferença entre parâmetros de cor com $5 \%$ de significância. compostos fenólicos pode ter se dado pelo aumento da eficiência da extração desses compostos com o aumento da irradiação. Por outro lado, a dose de 15,0 kGy pode ter sido suficiente para degradar os compostos fenólicos presentes na amostra. As amostras irradiadas com 7,5 e 10,0 kGy apresentaram diferenças significativas em nível de $5 \%$ quando comparadas ao grupo controle. O cultivar IAC-Runner 886 não apresentou diferenças significativas entre os tratamentos e o grupo controle. Apresentou comportamento semelhante ao cultivar IAC-Tatu ST com o aumento da dose de radiação. Porém, no cultivar IAC-Runner 886 o decaimento da concentração de compostos fenólicos se iniciou com a dose de 10,0 kGy.

\subsection{Atividade antioxidante pelo método $\mathrm{DPPH}$}

A Tabela 4 apresenta os dados referentes à porcentagem de atividade antioxidante dos amendoins tratados, utilizando-se o método DPPH.

O cultivar IAC-Tatu ST não apresentou diferença significativa em nível de 5\%, enquanto que o cultivar IACRunner 886 apresentou diferença entre o controle e o de irradiação com dose de 15,0 kGy.

\subsection{Atividade antioxidante pelo método ABTS}

A Tabela 5 apresenta os dados referentes à atividade antioxidante dos amendoins tratados, utilizando-se o método ABTS.

Pelo método ABTS, confirmamos que a irradiação de amendoim não ocasiona diferenças significativas na atividade antioxidante dos cultivares estudados.

\subsection{Perfil de ácidos graxos}

As Tabelas 6 e 7 apresentam os dados referentes ao perfil de ácidos graxos dos amendoins tratados, utilizando-se cromatografia gasosa.

As Tabelas 6 e 7 evidenciam que houve aumento na porcentagem de ácido linoleico em ambos os cultivares, este ácido é precursor de ácidos graxos de cadeia muito longa que, segundo Martin et al. (2006), desempenham função no desenvolvimento e funcionamento do cérebro e da retina.

A Tabela 8 demonstra importantes resultados sobre os dois cultivares de amendoim irradiados na dose de 10,0 kGy, recomendada para a eliminação fúngica: a) a porcentagem de ácidos graxos saturados diminuiu em relação ao controle; b) a porcentagem de ácidos graxos insaturados aumentou em relação ao controle; e c) a relação oleico/linoleico diminuiu em relação ao controle. Nota-se também que o cultivar IACRunner 886 foi mais sensível à irradiação no que se refere à sua

Tabela 2. Efeitos da radiação gama nos parâmetros ${ }^{1}$ de cor do amendoim cultivar IAC-Runner 886.

\begin{tabular}{|c|c|c|c|c|c|}
\hline IAC-runner 886 & Controle & $5,0 \mathrm{kGy}$ & 7,5 kGy & 10,0 kGy & $15,0 \mathrm{kGy}$ \\
\hline $\mathrm{L}$ & $34,40 \pm 2,8^{b}$ & $40,91 \pm 2,8^{\mathrm{a}}$ & $36,48 \pm 2,0^{\mathrm{ab}}$ & $35,78 \pm 2,3^{b}$ & $38,85 \pm 6,1^{\mathrm{ab}}$ \\
\hline $\mathrm{C}$ & $28,03 \pm 1,8^{b}$ & $29,74 \pm 1,3^{\mathrm{ab}}$ & $29,21 \pm 1,3^{\mathrm{ab}}$ & $30,01 \pm 1,7^{\mathrm{ab}}$ & $30,97 \pm 1,9^{a}$ \\
\hline $\mathrm{H}^{\circ}$ & $0,935 \pm 0,1^{\mathrm{a}}$ & $0,956 \pm 0,0^{\mathrm{a}}$ & $0,930 \pm 0,1^{\mathrm{a}}$ & $0,932 \pm 0,0^{\mathrm{a}}$ & $0,952 \pm 0,0^{\mathrm{a}}$ \\
\hline
\end{tabular}

${ }^{1}$ Os dados são a média de nove repetições \pm desvio padrão; $\mathrm{e}^{2}$ Letras diferentes na horizontal indicam diferença entre parâmetros de cor com $5 \%$ de significância. 
Tabela 3. Teor de compostos fenólicos totais ${ }^{1}\left(\mathrm{mg}^{\mathrm{g}} \mathrm{g}^{-1}\right)$ nos dois cultivares de amendoim irradiados.

\begin{tabular}{|c|c|c|c|c|c|}
\hline Cultivares & Controle & $5,0 \mathrm{kGy}$ & $7,5 \mathrm{kGy}$ & $10,0 \mathrm{kGy}$ & $15,0 \mathrm{kGy}$ \\
\hline IAC-Tatu ST & $33,27 \pm 0,3^{\mathrm{dc} 2}$ & $40,65 \pm 0,1^{\mathrm{bc}}$ & $52,35 \pm 6,1^{\mathrm{ab}}$ & $58,60 \pm 7,3^{\mathrm{a}}$ & $23,32 \pm 9,9^{d}$ \\
\hline IAC-Runner 886 & $51,59 \pm 7,1^{\mathrm{a}}$ & $57,54 \pm 6,0^{\mathrm{a}}$ & $62,11 \pm 10,3^{\mathrm{a}}$ & $60,98 \pm 6,2^{\mathrm{a}}$ & $53,39 \pm 17,2^{\mathrm{a}}$ \\
\hline
\end{tabular}

${ }^{1}$ Os dados são a média de três repetições \pm desvio padrão; ${ }^{2}$ Letras diferentes na horizontal indicam diferença de teor de compostos fenólicos totais com $5 \%$ de significância.

Tabela 4. Porcentagem de atividade antioxidante ${ }^{1}$ pelo método DPPH para os dois cultivares de amendoim irradiados.

\begin{tabular}{cccccc}
\hline Cultivares & Controle & $5,0 \mathrm{kGy}$ & $7,5 \mathrm{kGy}$ & $10,0 \mathrm{kGy}$ & $15,0 \mathrm{kGy}$ \\
\hline IAC-Tatu ST & $51,90 \pm 15,2^{\mathrm{a} 2}$ & $42,42 \pm 16,3^{\mathrm{a}}$ & $41,06 \pm 17,5^{\mathrm{a}}$ & $57,44 \pm 8,8^{\mathrm{a}}$ & $31,85 \pm 4,6^{\mathrm{a}}$ \\
IAC-Runner 886 & $39,76 \pm 13,7^{\mathrm{b}}$ & $66,74 \pm 12,1^{\mathrm{ab}}$ & $68,63 \pm 22,6^{\mathrm{ab}}$ & $66,72 \pm 20,0^{\mathrm{ab}}$ & $82,58 \pm 3,3^{\mathrm{a}}$ \\
\hline
\end{tabular}

${ }^{1}$ Os dados são a média de três repetições \pm desvio padrão; ${ }^{2}$ Letras diferentes na horizontal indicam diferença de atividade antioxidante com $5 \%$ de significância.

Tabela 5. Atividade antioxidante ${ }^{1}$, em $\mu$ mol TEAC. $g^{-1}$ de amostra, pelo método ABTS para os dois cultivares de amendoim irradiados.

\begin{tabular}{cccccc}
\hline Cultivares & Controle & $5,0 \mathrm{kGy}$ & $7,5 \mathrm{kGy}$ & $10,0 \mathrm{kGy}$ & $15,0 \mathrm{kGy}$ \\
\hline IAC-Tatu ST & $5,54 \pm 0,1^{\mathrm{a} 2}$ & $5,63 \pm 0,0^{\mathrm{a}}$ & $5,65 \pm 0,0^{\mathrm{a}}$ & $5,60 \pm 0,0^{\mathrm{a}}$ & $5,62 \pm 0,1^{\mathrm{a}}$ \\
IAC-Runner 886 & $5,79 \pm 0,1^{\mathrm{a}}$ & $5,74 \pm 0,0^{\mathrm{a}}$ & $5,78 \pm 0,0^{\mathrm{a}}$ & $5,84 \pm 0,1^{\mathrm{a}}$ & $5,90 \pm 0,0^{\mathrm{a}}$ \\
\hline
\end{tabular}

${ }^{1}$ Os dados são a média de três repetições \pm desvio padrão; e ${ }^{2}$ Letras diferentes na horizontal indicam diferença de atividade antioxidante com $5 \%$ de significância.

Tabela 6. Porcentagem de ácidos graxos do cultivar IAC-Tatu ST irradiado.

\begin{tabular}{lccccccc}
\hline Tratamento & Ácido palmítico & Ácido esteárico & Ácido oleico & Ácido linoleico & Ácido araquídico & Ácido cis 11 eicosenoico & Ácido behênico \\
& $16: 0$ & $18: 0$ & $18: 1$ & $18: 2$ & $20: 0$ & $20: 1$ & $22: 0$ \\
\hline Controle & 15,36 & 3,56 & 38,17 & 33,08 & 0,80 & 1,50 & 1,02 \\
$5,0 \mathrm{kGy}$ & 17,29 & 3,53 & 38,30 & 35,43 & 0,67 & 0,96 \\
$7,5 \mathrm{kGy}$ & 17,19 & 3,94 & 38,58 & 34,56 & 0,72 & 1,02 & 1,11 \\
$10,0 \mathrm{kGy}$ & 15,09 & 3,35 & 39,39 & 35,50 & 0,80 & 1,20 \\
$15,0 \mathrm{kGy}$ & 15,36 & 3,27 & 39,66 & 36,20 & 0,85 & 1,11 \\
\hline
\end{tabular}

Tabela 7. Porcentagem de ácidos graxos do cultivar IAC-Runner 886 irradiado.

\begin{tabular}{lccccccc}
\hline Tratamento & Ácido palmítico & Ácido esteárico & Ácido oleico & Ácido linoleico & Ácido araquídico Ácido cis 11 eicosenoico Ácido behênico \\
& $16: 0$ & $18: 0$ & $18: 1$ & $18: 2$ & $20: 0$ & $20: 1$ & $22: 0$ \\
\hline Controle & 15,23 & 3,23 & 49,07 & 26,43 & 0,87 & 1,53 & 1,45 \\
$5,0 \mathrm{kGy}$ & 14,51 & 3,55 & 47,47 & 29,30 & 0,78 & 1,37 & 1,54 \\
$7,5 \mathrm{kGy}$ & 13,83 & 3,29 & 48,02 & 29,96 & 0,78 & 1 \\
$10,0 \mathrm{kGy}$ & 13,72 & 3,72 & 47,45 & 28,97 & 0,91 & 1,73 & 1,73 \\
$15,0 \mathrm{kGy}$ & 12,98 & 3,25 & 46,58 & 30,84 & 0,73 & 1,47 \\
\hline
\end{tabular}

Tabela 8. Somatória dos ácidos graxos saturados (TS), ácidos graxos insaturados (TI) e relação de Oleico/Linoleico em função da dose de radiação gama para os dois cultivares.

\begin{tabular}{ccccccccc}
\hline Tratamento & \multicolumn{3}{c}{ IAC-Tatu ST } & & \multicolumn{3}{c}{ IAC-Runner 886 } \\
\cline { 2 - 3 } \cline { 7 - 9 } & TS & TI & O/L & & TS & TI & O/L \\
\hline Controle & 20,91 & 72,75 & 1,15 & & 20,78 & 77,03 & 1,86 \\
$5,0 \mathrm{kGy}$ & 22,45 & 74,75 & 1,08 & & 20,35 & 78,14 & 1,62 \\
$7,5 \mathrm{kGy}$ & 23,05 & 74,16 & 1,12 & & 19,65 & 79,42 & 1,60 \\
$10,0 \mathrm{kGy}$ & 20,32 & 74,16 & 1,11 & & 20,06 & 77,75 & 1,64 \\
$15,0 \mathrm{kGy}$ & 20,56 & 76,97 & 1,10 & & 18,60 & 78,89 & 1,51 \\
\hline
\end{tabular}

relação oleico/linoleico. Entretanto, verificando dados de Chiou, Lin e Shyu (1990) com irradiação de amendoim Tainan \#9, um cultivar espanhol, nota-se que para este cultivar a relação oleico/linoleico teve pouca alteração com as mesmas doses de irradiação, o total de ácidos graxos saturados e insaturados teve o mesmo comportamento decrescente e crescente, respectivamente, na dose de 10,0 kGy.

\section{Conclusões}

A irradiação nas doses utilizadas não influenciou a cor do cultivar IAC-Tatu ST, porém influenciou a luminosidade e o croma da variedade IAC-Runner 886 , com pouca intensidade. A irradiação tornou os compostos fenólicos totais mais disponíveis, com o seu decaimento a partir de doses mais altas; 15,0 kGy para o IAC-Tatu ST e 10,0 kGy para o IAC-Runner 886. A atividade antioxidante não sofreu alterações significativas, em ambos os cultivares, na dose de 10,0 kGy, recomendada para eliminação fúngica segundo os dois métodos utilizados. A irradiação alterou o perfil de ácidos graxos, diminuindo a porcentagem de ácidos graxos saturados, aumentou a porcentagem de ácidos graxos insaturados e aumentou a porcentagem de ácido linoleico, precursor de ácidos graxos de cadeia muito longa que atuam no desenvolvimento e funcionamento do cérebro e da retina. A relação oleico/linoleico diminuiu em todos os tratamentos em relação ao controle, o que pode ser amenizado pela atividade antioxidante que não sofreu alterações significativas. A partir desses resultados, justificam-se novas pesquisas para 
se conhecer a estabilidade autoxidativa dos lipídios durante o armazenamento prolongado.

\section{Agradecimentos}

À COPERCANA (Cooperativa dos Plantadores de Cana do Oeste do Estado de São Paulo) de Sertãozinho-SP pela doação dos cultivares de amendoim. Ao Prof. Dr. Severino Matias de Alencar e à Técnica Ivani Moreno pela leitura dos ácidos graxos e à Prof ${ }^{a}$ Dra Marta Helena Fillet Spoto e à Técnica Silvana Albertini pela realização da análise de cor.

\section{Referências bibliográficas}

ARTS, M. J. T. J. et al. A new approach to assess the total antioxidant capacity using the TEAC assay. Food Chemistry, v. 88, n. 4, p. 567-570, 2004.

BERG, V. D. et al. Applicability of an improved Trolox equivalent antioxidant capacity (TEAC) assay for evaluation of antioxidant capacity measurements of mixtures. Food Chemistry, v. 66, p. 511-517, 1999.

BRAND-WILLIAMS, W., CUVIER, M. E.; BERSET, C. Use of a free radical method to evaluate antioxidant activity. LebensmittelWissenschaft \& Technologie, v. 28, p. 25-30, 1995.

CHIOU, R. Y. Y.; LIN , C. M.; SHYU, S. L. Property characterization of peanut kernels subjected to gamma irradiation and its effect on the outgrowth and aflatoxin production by Aspergillus parasiticus. Journal of Food Science, v. 55, n. 1, p. 210-213, 1990.

COUNCIL FOR AGRICULTURAL SCIENCE AND THECNOLOGY - CAST. Micotoxins: risks in plant, animal and human systems. Ames, 2003. 109 p. Task Force Report, 139.

DULLEY, R. D. Algumas considerações sobre alimentos irradiados. Informações Econômicas, v. 32, n. 8, p. 17-27, 2002.

FAGUNDES, H. F. Sementes de amendoim: alguns comentários. 2002. Disponível em: <http:/www.conab.gov.br/conabweb/download/ cas/especiais/semente_de_amendoim_internet.pdf $>$. Acesso em: 01 jul. 2007.

FOLCH, J.; LEES, M.; STANLEY, G. H. S. A simple method for the isolation and purification of total lipids from animal tissues. Journal of Biological Chemistry, v. 726, p. 497-509, 1957.

KRAMER, J. K. G. et al. Evaluating acid and base catalysts in the methylation of milk and rumen fatty acids with specialemphasis on conjugated dienes and total trans fatty acids. Lipids, v. 32, p. 1219-1228, 1997.

MARTIN, C. A. et al. Ácidos graxos poliinsaturados ômega-3 e ômega-6: importância e ocorrência em alimentos. Revista de Nutrição, v. 19, n. 6, 2006. Disponível em: <http://www.scielo.br/ scielo.php?script $=$ sci_arttext\&pid=S1415-52732006000600011\&ln $\mathrm{g}=$ pt\&nrm=iso $>$. Acesso em: 03 mar 2008.

MARTINS, R. Amendoim: perspectivas para a safra 2007/2007. Análises e Indicadores do Agronegócio, v. 2, n. 10, 2007. Disponível em: $<$ http://www.iea.sp.gov.br/out/vertexto.php?codTexto=9095 $>$. Acesso em: 16 jul. 2008.

PRADO, G. et al. Efeito da irradiação $\left({ }^{60} \mathrm{Co}\right)$ na freqüência fúngica de amendoim in natura em função do tempo de prateleira. Ciência e Agrotecnologia, v. 30, n. 5, p. 930-936, 2006.

RE, R. et al. Antioxidant activity applying an improved ABST radical cation decolorization assay. Free Radical Biology, v. 26, n. 9/10, p. 1231-1237, 1999.

SANTOS, R. C.; GONDIM, T. M. S.; FREIRE, R. M. M. Cultivo de amendoim: mercado e comercialização. Sistemas de Produção, n. 7, 2006. Disponível em: <http://sistemasdeproducao.cnptia.embrapa. br/FontesHTML/Amendoim/CultivodoAmendoim/index.html>. Acesso em: 01 jul. 2007.

SWAIN, T.; HILLIS, W. E. The phenolic constituents of Prunus domestica I.- The Quantitative Análysis of. Phenolic Constituents. Journal of the Science of Food and Agriculture, v. 10, p. 63-68, 1959.

TASSO JUNIOR, L. C.; MARQUES, M. O.; NOGUEIRA, G. A. A cultura do amendoim. Jaboticabal: UNESP, 2004. 220 p.

TOLEDO, T. C. F. et al. Composição, digestibilidade protéica e desaminação em cultivares brasileiras de soja submetidas à radiação gama. Ciência e Tecnologia de Alimentos, v. 27, n. 4, 2007. Disponível em: <http://www.scielo.br/scielo.php?script=sci_ arttext\&pid=S0101-20612007000400022\&lng=pt\&nrm $=$ iso $>$. Acesso em: 04 mar. 2008.

VASCONCELOS, S. M. L. et al. Reactive oxygen and nitrogen species, antioxidants and markers of oxidative damage in human blood: main analytical methods for their determination. Química Nova, v. 30, n. 5, 2007. Disponível em: <http://www.scielo.br/scielo. php?script=sci_arttext\&pid=S0100-40422007000500046\&lng=en \&nrm=iso >. Acesso em: 04 mar 2008.

WILSON, D. M. Management of mycotoxins in peanuts. In: MELOUK, H. A.; SHOKES, F. M. (Ed.). Peant health management. St. Paul: APS PRESS, 1995. cap. 13, p. 87-92. 